\title{
Alegoria e melancolia nas obras poéticas de Luís Quintais e Francisco Alvim
}

\author{
Allégorie et mélancolie dans les cuvres poétiques \\ de Luís Quintais et Francisco Alvim
}

Deyse dos Santos Moreira

Université Paris Sorbonne/Universidade Federal Fluminense

\section{DOI}

https://doi.org/10.37508/rcl.2020.n44a39o

RESUMO

Este artigo propõe uma análise comparada entre alguns poemas de Luís Quintais (1968), poeta português que estreou, em 1995, com o livro A imprecisa melancolia, e de Francisco Alvim (1938), poeta brasileiro que publicou seu primeiro livro, Sol dos cegos, em 1968. Pretende-se estudar a interseção entre a expressão alegórica, marcada pela linguagem fragmentária e pelo fluxo temporal descontínuo, e o olhar melancólico que traz a dimensão da perda de sentido, ou do tempo morto e irrecuperável, contribuindo assim com os diálogos literários entre Brasil e Portugal.

Palavras-chave: Francisco Alvim; Luís Quintais; poesia contemporânea; melancolia; alegoria.

\section{RÉSUMÉ}

Cet article propose une analyse comparative de quelques poèmes de Luís Quintais (1968), poète portugais qui a publié, en 1995, son premier livre $A$ imprecisa melancolia, et de Francisco Alvim (1938), poète brésilien dont le premier ouvrage Sol dos cegos a été édité en 1968. Il intègre une étude sur l'expression allégorique, marquée par un langage fragmentaire et un flux temporel discontinu, et le regard mélancolique qui se penche sur la perte de sens ou du temps perdu, contribuant ainsi aux dialogues littéraires 
entre le Brésil et le Portugal.

Mots-CLÉs: Francisco Alvim; Luís Quintais; poésie contemporaine ; mélancolie ; allégorie.

O traço narrativo e descritivo que caracteriza grande parte da obra poética de Francisco Alvim e de Luís Quintais evidencia dois aspectos significativos da expressão alegórica articulada com o olhar melancólico: o fluxo temporal, como experiência da finitude e da transitoriedade, e a fragmentação, como processo de escrita descontínuo que tornará o cenário sempre incompleto. Comecemos por analisar esses elementos em dois poemas do poeta português:

O ANDORINHÃO-NEGRO

Mas existem andorinhões-negros em Lisboa?, e que importância é que isso tem?

Às vezes imagino o andorinhão-negro percorrendo veloz as ruas de Lisboa, deixando para trás o fim do Verão, regressando às zonas meridionais, acendendo uma réstea de calor na planície, afugentando a passagem para uma outra hora, um outro ritmo nascendo na distância, Áfricas do longe chegando suavemente ao abrigo do voo.

Às vezes imagino que recortaram uma ave na paisagem, que a deixaram suspensa sobre o tempo, e que o tempo não passou para que a luz a sustentasse devagar nos céus, e o azul mediterrânico à beira-mar gravitasse noite adentro sem escurecer, e a terra não fosse um leito de morte, mas uma melodiosa 
morada

(QUINTAIS, 2015, p. 756)

Entre a primeira e a segunda estrofes, observamos experiências temporais diferentes. Das Áfricas à Lisboa, o deslocamento migratório da ave agrega movimento ao cenário da primeira estrofe. Temos aqui a experiência do tempo que passa, "voa", implicando dessemelhança entre o que foi e o que é. Assim se delineia o imaginário da ave, circunscrito na distância de sua origem. Neste intervalo, a imagem do andorinhão-negro vai remeter a um tempo outro, já que mesmo a imaginação desenha um outro ritmo e apenas faz acender "uma réstea de calor na planície", com se o vestígio da imagem familiar de um verão passado esboçasse um acalento na pele do sujeito e pudesse abrigá-lo da passagem do tempo.

$\mathrm{Na}$ segunda estrofe, quase temos a impressão de que, de fato, a imagem da ave recortada na paisagem evocará um refúgio, ou seja, uma possibilidade unitiva entre o passado e o presente, suspendendo o tempo para culminar na experiência simultânea e totalitária do símbolo. Se a estrutura simbólica é a da sinédoque, como assinalou Paul de Man (1999), o símbolo é sempre parte da totalidade que representa, de modo que "na imaginação simbólica, não tem lugar nenhuma disjunção entre faculdades constitutivas" (DE MAN, 1999, p. 212). Ou seja, a imagem da ave, do ponto de vista simbólico, promoveria uma relação de continuidade entre o passado e o presente, como parte do todo comum da vida do sujeito. Entretanto, a melodiosa morada é apenas uma ilusão momentânea. Os últimos versos assinalam a temporalidade como experiência da finitude, de modo que a terra, mundo e corpo do sujeito não configuram uma morada ou abrigo, mas sim “um leito de morte". A propósito do fluxo temporal na relação entre os signos, o qual estrutura a expressão alegórica, Paul de Man (1999), na mesma direção de Benjamin (2009), explica que ele é incontornável na medida em que o signo alegórico refere- 
-se sempre a outro que o precede, com o qual não irá igualar-se: “O significado constituído pelo signo alegórico só pode então consistir na repetição (no sentindo kierkegaardiano do termo) de um signo anterior com o qual não pode nunca coincidir" (DE MAN, 1999, p. 227). Dessa maneira, a temporalidade alegórica promove um efeito de negativo:

Enquanto o símbolo postula a possibilidade de uma identidade ou de uma identificação, a alegoria designa sobretudo uma distância em relação à sua própria origem, e, renunciando à nostalgia e ao desejo de coincidência, estabelece a sua linguagem no vazio dessa diferença temporal. Ao fazê-lo, impede uma identificação ilusória entre o eu e o não-eu que é agora plenamente, ainda que dolorosamente, reconhecido como não-eu (DE MAN, 1999, p. 227).

No prisma alegórico, a imagem fixa da ave recortada na paisagem, suspendida no tempo, torna-se emblema para se falar de outra coisa ausente. Ela é um fragmento desconexo que não alude ao todo, promovendo uma descontinuidade entre o passado e o presente, uma intermitência entre presença e falta. A imagem torna-se "um mero fantasma" (DE MAN, 1999, p. 212), ruína que jaz como experiência da distância, remetendo a qualquer coisa que já não está presente. Daí o emblema enquanto imagem morta, ao contrário do símbolo que é imagem orgânica. À vista disso, a imagem da ave alude à história ocultada nos versos, à vivência nas Áfricas, a uma provável migração do sujeito a Lisboa e sua busca por abrigo.

A epígrafe do poema - "Mas existem andorinhões-negros em Lisboa?, / e que importância é que isso tem?” - , para além de referir a uma cisão entre percepção e realidade, lembra que a ave escolhida para o registro é a espécie que passa a maior parte do tempo a voar, deslocando-se constantemente, podendo ficar até dez meses sem pousar. Essa informação é interessante para refletirmos sobre o fragmento que temos da narrativa do sujeito: sua migração e de- 
senraizamento, já que não encontra morada. Nesse sentido, é igualmente interessante o destaque ao único verso que compõe a terceira estrofe: "morada", como se reforçasse a sua ausência. O emblema, assim, remete a um tempo e espaço perdidos, evidenciando o olhar melancólico, de estranhamento. Fixado na imagem da ave - em si uma clivagem do real - o sujeito contempla o vazio que ela descortina, como um memento mori a apontar para sua própria desaparição. Dessa imagem, desse olhar contemplativo que rumina uma ave aparentemente sem função no cenário de Lisboa, somos lançados para uma dimensão reflexiva que nos faz pensar sobre o (não) lugar de habitação do ser no mundo. Desse modo, o olhar melancólico, submerso no fragmentário, ao contrário de culminar na inércia e na completa falta de sentido, produz saber, produz outra imagem abstrata, mas significativa. É exatamente este o movimento da linguagem alegórica: ressignificar.

O fluxo temporal e a narrativa descontínuos que estruturam a linguagem alegórica expressam, portanto, a historicidade biográfica, e não o instante místico, como assinalou Benjamin (2009). Nessa perspectiva, podemos ler outro poema de Luís Quintais:

Como chegámos a este lugar? A guerra deflagrava em todas as regiões deste mapa que nos iria desenhar, a nós, ponto a ponto, semelhança a semelhança. Famílias reuniam bagagens, despediam criados, fugiam apavoradas por estradas tomadas de assalto pela vegetação densa. Impropriedade do medo, negras margens do remorso. Rompiam-se sacos placentários, criaturas atiradas para a rua do sem-regresso berravam a sua inviolável linguagem, precipitavam-se de encontro ao muro denso da história, exigiam um nome, um símbolo apodrecendo na eleição de um cacifo, uma caixa onde depositariam a sua fragmentada posse, o seu saque (2015, p. 71).

A narração inicia-se evocando um espaço atual. A questão da chegada a este espaço desdobra-se no enunciado de uma história pas- 
sada, de migração. Do fato concreto, famílias fugindo da guerra, passamos a uma dimensão abstrata, o medo e um possível arrependimento. A reflexão, que interrompe a história, evoca um percurso sem volta, além de enfatizar um perigo iminente. Em seguida, temos o registro do nascimento de crianças, como último fragmento do campo narrativo, novamente interrompido por reflexões as quais se desviam da questão inicial do poema. Em seus desvios, o texto nos convida a refletir sobre a temporalidade "sem-regresso" e sobre o desamparo do ser humano desde seu nascimento, sempre à procura de abrigo e de elementos com os quais possa traçar sua história e identidade. No entanto, o próprio nome, elemento importante da biografia do sujeito, é um arbitrário “símbolo apodrecendo”, imagem que se afasta da ideia de símbolo como possibilidade de identificação, ou sinal dos deuses, fulgurante e totalizador: "Nas situações decisivas da vida, em que cada instante esconde um futuro prenhe de consequências e mantém a alma em tensão nos momentos fatídicos, também os Antigos viviam na expectativa dos sinais dos deuses, a que chamavam... symbola" (BENJAMIN, 2009, p. 174). No poema, o nome é ruína, marcado pelo seu fim, revelando o percurso decadente do sujeito e a degradação de si próprio. Vale lembrar que Benjamin (2009) assinala que a imagem alegórica por excelência é a ruína, tendo em vista que o processo alegórico de ressignificação, em sua dialética entre destruição e construção de sentido, singulariza o objeto, destituindo-o de seu significado e contexto iniciais para mostrá-lo como fragmento, desfazendo assim qualquer ilusão de totalidade.

Se as ruínas, no "reino das coisas”, marcam o que já se perdeu, mas que persiste em seu inacabamento e decomposição, provocando um paradoxo entre presença e ausência, ruptura e continuidade, o olhar alegórico, ao projetar numa imagem o que dela falta, promove não apenas uma transposição semântica, mas um sobressalto temporal, trazendo a dimensão de um tempo outro. Nesse sentido, a alego- 
ria, "no reino dos pensamentos" (BENJAMIN, 2009, p. 189), pode ser associada, por um lado, ao funcionamento descontínuo da memória; por outro lado, os momentos de suspensão de sentido, inerentes ao movimento fragmentário da alegoria, "obriga o leitor a deter-se em 'estações' para refletir” (BENJAMIN, 2009, p. 17), de modo que as ruínas, enquanto objetos de contemplação, instigam a imaginação, promovendo novos sentidos e novas combinações, como fragmentos que abrigam um mistério. Assim, a expressão alegoria seria uma representação contemplativa cujo objetivo não é o de entusiasmar o leitor, e sim de investigar as ideias, de mobilizar associações constantemente renovadas do pensamento:

O pensamento volta continuamente ao princípio, regressa com minúcia à própria coisa. Este infatigável movimento de respiração é o modo de ser específico da contemplação. De fato, seguindo na observação de um único objeto, os seus vários níveis de sentido, ela recebe daí, quer o impulso para um arranque constantemente renovado, quer a justificação para a intermitência do seu ritmo. Ambos se compõem de elementos singulares e diferentes (...). O valor dos fragmentos de pensamento é tanto mais decisivo quanto menos imediata é a sua relação com a concepção de fundo, e desse valor depende o fulgor da representação, na mesma medida em que o do mosaico depende a qualidade da pasta de vidro (BENJAMIN, 2009, p. 17).

Apesar do uso da metáfora para relacionar o nome à caixa e ao cacifo e assim criar um terceiro reino imagético do sujeito como recipiente de acúmulo de fragmentos apodrecendo, a própria imagem resultante dessa metáfora reflete o olhar do alegorista, colecionador de fragmentos, além de enfatizar, mais uma vez, o tempo que mata, que tudo destrói. Ademais, a macroestrutura do texto é apoiada pela expressão alegórica, tendo em vista que os desvios da narrativa promovem a correlação entre os planos concreto e abstrato, traduzindo um modo de expressão marcado pela impossibilidade de um regis- 
tro totalitário. Associando os dois poemas, podemos principiar um mosaico da história do sujeito poético: fuga da guerra, migração da África a Portugal... A forma poética minada nos propicia a recomposição da narrativa, sem que obtenhamos uma conjuntura original nem definitiva.

Em relação à escrita aparentemente direta desses poemas, os quais deixam menos evidente o trabalho poético em face de um registro de cunho narrativo e descritivo, Rosa Maria Martelo assinala a "fragilidade ontológica do próprio texto" (MARTELO, 2009, p. 13). Ao abordar a poesia portuguesa contemporânea, ela defende que esse aspecto "passa pela secundarização do papel da metáfora e pela construção de um modo de expressão essencialmente alegórico" (MARTELO, 2009, p. 13):

Contrariamente ao que fora apanágio do Modernismo, onde o poema se contrapunha à fragilidade e à ausência do mundo afirmando-se como manifestação de uma presença discursivamente densa, dir-se-ia que a poesia contemporânea se dissolve, também ela, num quadro generalizado de perda de espessura do real, do qual não parece poder separar-se (MARTELO, 2009, p. 13).

Martelo relaciona a ausência de uma discursividade "densa” da poesia à "perda de espessura do real", ou seja, ao registro da dissolução do mundo, culminando numa forma poética que, à primeira vista, se mostra como uma descrição do cotidiano, ocultando o trabalho estético. Esse aspecto observado na poesia portuguesa contemporânea pode ser igualmente encontrado na brasileira, como podemos observar nos seguintes poemas de Francisco Alvim.

DIÁRIO

O dia que traz consigo?

Arcas, roupas de baixo

livros sem capa 
versos alambicados

sapatos a que faltam cadarço

vogam pelo quarto

batem desencontrados

fazem um barulhão

dos diabos

que acorda os vizinhos

Domingo ou segunda-feira

há sempre missa

todos saem

O prédio fica vazio

no meio do bairro vazio

de uma cidade vazia

O poeta, sem vizinhança

Remotíssima criatura

levanta-se, vai à janela

e espia o pátio lá em baixo

Podia pensar um verso

podia, mas não pensa

(ALVIM, 2004, p. 370).

Um diário normalmente registra anotações, narrativas cotidianas. O poema abre-se como espaço de registro do fluxo dos dias, mas o enredo desponta desarticulado pela enumeração de objetos dispersos pelo quarto, com ar de abandono. Através dos sapatos, sem função no cenário, somos levamos a imaginar a vida que se movimenta lá fora, incômoda e igualmente desarticulada da figura desse sujeito (que é um poeta). O único vínculo parece ser o barulho dos sapatos e o olhar do sujeito, a espiar pela janela.

Se a passagem do tempo é realçada pela referência aos dias da semana, "Domingo ou segunda-feira" equivalem-se, expondo a temporalidade como repetição, movimento que reitera o vazio do enredo e a nulidade dos dias. Essa repetição - que esvazia tanto o cenário 
quanto o sentido ontológico da passagem do tempo - pode ser percebida pela sonoridade do poema, através do uso da epístrofe, com a repetição da palavra "vazio" no final dos versos abaixo, juntamente com a aliteração entre "vazio", "vazia" e "vizinhança":

O prédio fica vazio

no meio do bairro vazio

de uma cidade vazia

O poeta, sem vizinhança

Diante do esvaziamento de sua própria narrativa, o poeta contempla a vida de fora, a qual surge tão sem sentido quanto a sua, fadada a repetição. Se a missa poderia ser um espaço de possibilidade de sentido, de abertura para uma transcendência, ela surge como evento apenas capaz de mobilizar as pessoas a se deslocarem. Nem a missa escapa dessa lógica repetitiva e sem sentido, de modo que o poeta, "Remotíssima criatura", prefere espiar pela janela a frequentá-la. À vista desse vazio de dentro refletido no vazio de fora, o poeta descarta até mesmo a escrita, optando por não pensar em nada. No entanto, temos diante dos olhos uma composição poética, de modo que o dizer uma coisa querendo expressar outra destampa a chave irônica do poema, em seu vínculo com a alegoria, levando-nos a refletir sobre a utilidade da escrita diante dessa narrativa que é um nada; sobre a possibilidade de abertura da linguagem poética, de criação e de ressignificação. Em outras palavras, o cenário fragmentário, constituído a partir da dispersão imagética e do esvaziamento de sentido, destampa o olhar melancólico articulado ao "olhar do anotador de fragmentos" (QUINTAIS, 2015, p. 59), o olhar do alegorista, que transforma as imagens insignificantes em objetos de saber. Vinte anos após a escrita do poema "Diário", Francisco Alvim escreve outro poema com o mesmo título, reforçando a ideia de esvaziamento e descontinuidade da temporalidade, tornando a narrativa fragmento de coisa nenhuma: "DIÁRIO // 
O nada a anotar" (ALVIM, 2004, p. 146).

O gesto performático de escrever para assinalar que a escrita é dispensável e a existência é insignificante faz com que o registro se torne um testemunho dessa experiência de vazio, de modo que a escrita passa a ser muito significante: o poema irá configurar um espaço potente de reflexão do ser no mundo. Nessa mesma perspectiva, podemos ler o poema a seguir de Luís Quintais:

NADA

Eles estão sentados,

o mesmo copo, a mesma mesa,

a segura e indivisa

natureza

do sangue e da voz:

a mãe, o pai, o filho

de espinha bífida,

velhos, muito velhos

os três.

Dentro

do arnês

uma intimidade maior

que o tempo

os traz,

o mesmo copo,

a mesma mesa,

dias fora,

nada.

(2015, p. 123)

$\mathrm{Na}$ primeira estrofe, o registro descreve uma cena como se fosse uma fotografia: uma família sentada em torno de uma mesa. O fluxo temporal é sugerido no envelhecimento da mãe, do pai e do filho, e na repetição dos gestos quotidianos, evidenciada no uso dos objetos 
“o mesmo copo, a mesma mesa”. O tempo que passa, entretanto, não agrega progressão ao cenário. Ele deflagra a destruição dos corpos e a incontornável herança de uma falha, de uma anomalia.

Na segunda estrofe, passamos do plano descritivo ao reflexivo. Por meio do detalhe dos objetos aborda-se a subjetividade dos corpos, de modo que a partilha do copo e da mesa será o que há de mais íntimo, de mais humano no registro. Isso nos leva a associar a falha à própria natureza do ser, como se os corpos fossem apenas armaduras, coisificados. Ademais, a reiteração dos versos "o mesmo copo, / a mesma mesa", circunscreve o fluxo temporal como uma espiral cuja repetição dos dias assinala o vazio da existência, a perda de espessura do real observada por Martelo (2009). A composição surge, assim, como um fragmento de um enredo em falha, evidenciando um destino fatalista diante do qual será também constante a interrogação sobre a (in)utilidade das palavras na obra do poeta português.

O mosaico narrativo, em sua incompletude, está sempre a traçar desventuras do drama humano, com suas perdas inevitáveis e envelhecimento certeiro:

POLIANTEIA DO DR. SÁ

Mar cego

Na mesa do bar

agoniza -

sobrancelhas brancas -

o velho

Perdeu o navio

Como saber o itinerário

agora

se os mapas os jornais

não contêm indícios?

O velho dr. 
Um vago sentir

de outras tardes de outras

noites

Lá fora

o vento sul

nas amendoeiras

Notícias do navio

que perdeu

não chegam ao velho

Notícias da mulher

que perdeu

não chegam ao velho

Notícia dos filhos

que já o esqueceram

não chegam ao velho -

afinal

tão bom para o mar

Mar cego

viagem

Um berçário

cheio de moscas

Crianças com

lodo nos olhos

na boca

Lá fora

sopra o sudeste

Vento maligno

para o navio

Longe já vai

da enseada

o navio -

bicho nos corredores

do mar 
Quem o vê não

vê seu

rastro -

pisa leve

o bicho

Dentro do navio

corredores

Fora do navio o jardim

do mar

O mar o navio

qual senda a mais ampla?

Entre baixios

naufraga

o navio

Na mesa do bar

agoniza

o velho

Perdeu perdeu o

navio

o velho dr.

Um rio escuro

onde crianças

já o precederam

no pulo

Longe dali

naufraga

um navio

(ALVIM, 2004, p. 358-361).

O poema inicia-se expondo dois cenários em paralelo: um concreto, a mesa do bar; outro abstrato, o mar cego. No plano concreto, a 
personagem de um velho é introduzida na narrativa por uma metonímia, o detalhe das sobrancelhas brancas, reforçando sua idade avançada e evidenciando sua agonia, sua morte iminente. $\mathrm{Na}$ dimensão abstrata, temos a figura do navio, a qual alude à vida passada desse sujeito, a vida perdida. A expressão alegórica que estrutura o texto irá funcionar na correlação desses dois planos. Assim, na medida em que o "velho dr." se caracteriza por "Um vago sentir / de outras tardes de outras / noites", ele associa-se ao navio que é emblema de um tempo outro, irrecuperável. Nesse prisma, toda a trajetória do sujeito, sua viagem, desponta como imagem morta, náufraga. Temos aqui a experiência da perda, da distância: o navio está longe do abrigo, longe do porto, ele próprio perdido. Navio e sujeito aparecem como um bicho que se arrasta pelos corredores do mar, sem deixar rastro, de modo que se torna impossível reconstituir seu itinerário, sua história, sua biografia. Em face do apagamento da trajetória, o mar configura-se como espaço de vaguidão, de esquecimento. É isso que resta no tempo do presente: um "mar cego".

A viagem traduz, portanto, as inevitáveis perdas, a passagem do tempo sem regresso, do tempo que destrói:

\author{
Um berçário \\ cheio de moscas \\ Crianças com \\ lodo nos olhos \\ na boca
}

Se o mar é o espaço por onde, num tempo já morto, trafegou o navio, este também surge como espaço interior do sujeito, com seus corredores a transitar pensamentos e sensações, igualmente impossíveis de reconstituir. Nesse sentido, navio e mar aproximam-se aludindo a uma história perdida, de si próprio e do mundo que o envolve. Perdido o espaço navegável, que implica movimento, ele torna-se jardim, terra intransitável para um navio. Ao longo da nar- 
ração, os obstáculos no percurso, os escolhos, fazem com que o navio naufrague e provocam uma intermitência em nosso olhar: enxergamos o desaparecer do velho em uma mesa de um bar - plano concreto - e tudo aquilo que com ele finda - plano abstrato. Nessa perspectiva, as três últimas estrofes reiteram a perda de toda uma vida passada, longe dali, da mesa do bar, sendo a figura do velho um vestígio. No fim do poema, já não há mar, apenas um rio escuro que nada reflete, nada faz emergir. Ao contrário, configura um espaço onde a vida fracassada do sujeito, seu corpo agonizante, irá afundar.

O desfecho da temporalidade como experiência da finitude e da narrativa como um enredo em falha nos remete ao título do poema, tornando interessante a indefinição em que culmina a designação do Dr. Sá, nome especificado no título, mas diluído num anonimato em face da menção variável de "o velho" ou "o velho dr.". Ou seja, a especificidade do nome desaparece do enredo, evidenciando a impossibilidade de reconstituição da história, do rastro, do trajeto. A figura do Dr. Sá, assim como a do navio, é uma ruína, de modo que a antologia, coleção de memórias e de anedotas que deveria ser o relato do poema, revela-se como uma compilação de perdas. O único evento notável dessa "Polianteia" parece ser o próprio naufrágio do sujeito.

As análises textuais, portanto, evidenciam que a expressão alegórica, como técnica de escrita fragmentária, impossibilita a representação totalizante do instante absoluto - sobretudo em poemas mais longos - , estruturando-se a partir de um fluxo temporal intermitente. O que temos é a experiência da distância: o amálgama de imagens desconexas e o foco nos detalhes remete ao que falta, àquilo que já não é. Olhamos os estilhaços de imagens e avistamos outros cenários ausentes e irrecuperáveis. Esse movimento mobiliza o cruzamento de tempos diversos e desarticulados, evidenciando igualmente o olhar melancólico. Desse modo, os poemas não apontam para uma progressão da narrativa, a qual, ao contrário, sofre cons- 
tantes desvios. No entanto, os cenários poéticos não culminam em paralisia. Os momentos de suspensão de sentido deslocam o olhar melancólico de sua posição inerte, esvaziada, promovendo um potente jogo de ressignificação que nos leva a refletir sobre a própria poesia e sua capacidade de testemunhar o ser no tempo.

RECEBIDO: 31/03/2020 APROVADO: 07/10/2020

\section{REFERÊNCIAS}

ALVIM, Francisco. Poemas (1968-200o). Cosac Naify: Rio de Janeiro, 2004 .

BENJAMIN, Walter. Origem do drama trágico alemão (1928). Tradução João Barrento. São Paulo: Autêntica, 2009.

DE MAN, Paul. A retórica da temporalidade. In: O ponto de vista da cegueira. Tradução Miguel Tamen. Lisboa: Cotovia, 1999.

MARTELO, Rosa Maria. O olhar do alegorista na poesia portuguesa contemporânea, Portuguese Cultural Studies, v. 2, p. 12-22, 2009. Disponível em: https://scholarworks.umass.edu/p/vol2/iss1/3/. Acesso em: 19 out. 2020.

QUINTAIS, Luís. Arrancar penas a um canto de cisne - Poesia 2015-1995. Lisboa: Assírio \& Alvim, 2015.

\section{MinicurRículo}

Deyse dos Santos Moreira é doutoranda na Sorbonne Université - Paris IV, em cotutela com a Universidade Federal Fluminense. Desenvolve pesquisa sobre poesia contemporânea brasileira e portuguesa. Tese intitulada "Alegoria e melancolia nas obras de Francisco Alvim e de Luís Quintais”. Mestre pela Université Sorbonne Nouvelle Paris 3 (2013). Em 2012, realizou parte dos estudos do mestrado na Faculdade de Letras da Universidade do Porto como bolsista Erasmus Mundus. Possui graduação em Letras pela Universidade de São Paulo (2011). 